\title{
Correction to: Interventional Radiological Treatment of Pediatric Liver Transplantation Complications
}

\author{
Jan H. Peregrin ${ }^{1}\left(\mathbb{D} \cdot\right.$ Jozef Kováć $^{1} \cdot$ Martin Prchlík $^{2} \cdot$ Pavel Heinige $^{2}$ • \\ Radana Kotalová $^{3} \cdot$ Jiří Froňek $^{4} \cdot$ Róbert Novotný $^{4} \cdot$ Matěj Kočík $^{4} \cdot$ \\ Libor Janoušek ${ }^{5}$
}

Published online: 4 March 2020

(C) Springer Science+Business Media, LLC, part of Springer Nature and the Cardiovascular and Interventional Radiological Society of Europe (CIRSE) 2020

\section{Correction to: Cardiovasc Intervent Radiol https://doi.org/10.1007/s00270- 020-02430-8}

In the original article, the following author name was incorrectly published and the corrected name is given below:

Incorrect author name: Radana Kotanová.

Corrected author name: Radana Kotalová.
Publisher's Note Springer Nature remains neutral with regard to jurisdictional claims in published maps and institutional affiliations.

The original article can be found online at https://doi.org/10.1007/ s00270-020-02430-8.

Jan H. Peregrin

jan.peregrin@ikem.cz

1 Department of Diagnostic and Interventional Radiology, Institute for Clinical and Experimental Medicine, Vídeňská 1958/9, 14021 Prague 4, Czech Republic

2 Department of Pediatric and Trauma Surgery Third Faculty of Medicine, Charles University, Thomayer Teaching Hospital, Vídeňská 800, 14059 Prague 4, Czech Republic

3 Department of Pediatrics, Charles University, Second Faculty of Medicine, Motol University Hospital, V Úvalu 84, 15006 Praha 5, Czech Republic

4 Transplant Surgery Department, Charles University, Second Faculty of Medicine, Institute for Clinical and Experimental Medicine, Vídeňská 1958/9, 14021 Prague 4, Czech Republic

5 Transplant Surgery Department, Charles University, First Faculty of Medicine, Institute for Clinical and Experimental Medicine, Vídeňská 1958/9, 14021 Prague 4, Czech Republic 